\title{
Factors associated with sleep disturbances in women undergoing treatment for early-stage breast cancer
}

\author{
Susan Grayson ${ }^{1}$ (1) $\cdot$ Susan Sereika ${ }^{1} \cdot$ Caroline Harpel $^{1,2} \cdot$ Emilia Diego $^{3} \cdot$ Jennifer G. Steiman $^{3} \cdot$ Priscilla F. McAuliffe $^{1}$. \\ Susan Wesmiller ${ }^{1}$
}

Received: 9 March 2021 / Accepted: 19 June 2021 / Published online: 10 July 2021

(c) The Author(s), under exclusive licence to Springer-Verlag GmbH Germany, part of Springer Nature 2021

\begin{abstract}
Purpose The purpose of this study was to examine factors associated with sleep disturbance in women receiving adjuvant therapy for breast cancer.

Methods This study employed a cross-sectional design using data collected at 3 months post-surgery from an ongoing longitudinal parent study. Participant data were divided into adjuvant treatment groups (chemotherapy, radiation, and aromatase inhibitors) and no adjuvant treatment groups. Symptoms were measured using patient self-report measures. Analysis of variance was used to assess between adjuvant treatment group differences in sleep disturbance. Regression analysis was performed to assess the relationship between sleep disturbance and other symptoms within adjuvant treatment groups.

Results The sample included 156 women diagnosed with early-stage breast cancer. There were significant differences in levels of reported sleep disturbance between treatment groups $(p=0.049)$, with significantly higher levels of sleep disturbances in those receiving radiation compared to those receiving no adjuvant treatment $(p=0.038)$ and in those receiving chemotherapy and those receiving no adjuvant treatment $(p=0.027)$. Increased sleep disturbance was found to be a significant predictor for increased pain severity, nausea severity, anxiety, depressive symptoms, fatigue, decreased physical function, and decreased ability to participate in social roles and activities. Co-occurring symptoms with sleep disturbance differed between adjuvant treatment groups. Sleep disturbance was also associated with younger age $(p=0.008)$.

Conclusions Patients undergoing chemotherapy or radiation for breast cancer report higher levels of sleep disturbance than those not receiving adjuvant therapy. Sleep disturbance is associated with other symptoms experienced by patients with cancer and thus requires continual assessment and future research into effective interventions.
\end{abstract}

Keywords Breast cancer $\cdot$ Sleep disturbance $\cdot$ Patient-reported outcomes

\section{Background}

Sleep disturbance is a common complaint among women undergoing treatment for early-stage breast cancer. More than $70 \%$ of patients with breast cancer undergoing chemotherapy report sleep disturbances [1], and over $85 \%$ of patients undergoing radiation for breast cancer have

Susan Grayson

Scw51@pitt.edu

1 School of Nursing, University of Pittsburgh, Pittsburgh, PA, USA

2 Graduate School of Public Health, University of Pittsburgh, Pittsburgh, PA, USA

3 School of Medicine, University of Pittsburgh, Pittsburgh, PA, USA abnormally frequent nighttime awakenings [2]. Sleep disturbance can persist beyond the course of treatment, with a recent meta-analysis finding a pooled prevalence of 0.40 in breast cancer survivors [3].

Sleep disturbance has been identified as part of a symptom cluster with pain and fatigue, which emerges in women receiving chemotherapy for breast cancer and can continue after the cessation of treatment [4]. A symptom cluster has been defined as "three or more concurrent symptoms that are related to each other but are not required to share the same etiology" [5]. The relationship between sleep disturbance and pain in patients with breast cancer appears to be complex and multidirectional, with decreased sleep quality prior to breast cancer surgery being associated with increased post-operative pain and increased analgesic requirements [6]. Prior to surgery, 
more women with breast pain reported clinically significant levels of sleep disturbance than those without breast pain [7]. Additionally, pretreatment sleep disturbance has been associated with increased pain in patients receiving radiation therapy for breast cancer [8]. The relationship between fatigue and sleep disturbance in patients with breast cancer may be multifaceted, with fatigue demonstrating significant association with subjective measures of poor sleep, but not with objective measures of sleep quality using actigraphy [9].

Associations have also been demonstrated between sleep disturbance and symptom burden in this patient population. In patients receiving chemotherapy, trait anxiety, depressive symptoms, decreased functional status, and evening fatigue have all been associated with higher levels of sleep disturbance [10]. In patients with gastrointestinal cancer, shorter sleep duration was significantly associated with fatigue, pain, anxiety, depression, and decreased quality of life [11]. Additionally, chemotherapy-induced nausea and vomiting has been associated with poor sleep quality in patients with breast cancer [12]. Nausea is also a significant predictor of cancer-related fatigue, a relationship mediated by the effect of nausea on sleep disturbance [13]. Poor sleep quality has also been associated with lower functional status and decreased quality of life in individuals with a cancer diagnosis $[14,15]$.

Suggested guidelines for the treatment in sleep disturbance in patients with cancer suggest treatment of risk factors such as pain, depression, and anxiety [16]. However, guidelines fail to clarify the best treatment methods for these risk factors in the context of sleep disturbance and cancer, highlighting the need for further understanding of these cooccurring symptoms. Furthermore, the treatment algorithm does not include nausea or poor functional status as risk factors to address in the treatment of sleep disturbance.

Chemotherapy treatment has been implicated in the development of sleep disturbance. One study found that breast cancer survivors reporting sleep duration changes were 2.64 times more likely to have received chemotherapy than survivors with no change in sleep duration [17]. Women who received chemotherapy for breast cancer also reported higher levels of sleep disturbance, fatigue, and depression than women who did not receive chemotherapy [18]. Studies of sleep disturbance trajectories show that a subset of patients experience increasing sleep disturbance during chemotherapy treatment for breast cancer [1]. Additionally, many of the referenced studies investigating sleep disturbance and its relation to other symptoms were completed in patients receiving chemotherapy; literature examining sleep disturbance in the context of radiation therapy is comparatively sparse. In one study among men with prostate cancer, however, self-reported sleep disturbance was found to increase during radiation treatment [19].
Though there is limited information on the relationship between sleep disturbance and radiation therapy, particularly among patients with breast cancer, studies have shown that symptom clusters emerging at the end of radiation treatment included decreased wellbeing, depression, and anxiety; nausea and decreased appetite; and drowsiness and dyspnea [20]. Previous studies suggest that sleep disturbance co-occurs with these symptoms, supporting the examination of sleep disturbance in the population of patients with breast cancer who are receiving radiation therapy. Aromatase inhibitor (AI) therapy for breast cancer has also been implicated in development of sleep disturbance, with insomnia complaints exceeding $50 \%$ in women taking an AI [21]. However, review of the literature revealed a lack of research investigating how sleep disturbance may differ among women receiving chemotherapy, radiation, AI therapy, or no adjuvant therapy.

Patient characteristics may also be associated with sleep disturbance in patients with cancer. Younger age has been associated with increased sleep disturbance [15, 22-24], although other studies have found no association between age and sleep disturbance in patients with breast cancer [1]. Additionally, a large $(n=12,098)$ longitudinal study found that breast cancer diagnosis was not significantly related to decreased sleep quality compared to pre-diagnosis, although sleep quality continued to decrease over time [25]. This would indicate that study participants would report poorer sleep quality as they aged. Higher body mass index (BMI) has also been found to be associated with increased subjective and objective sleep disturbance $[2,10]$.

The primary aim of this secondary analysis was to investigate differences in self-reported sleep disturbance between patients currently receiving chemotherapy, AI therapy, radiation, or no adjuvant treatment for breast cancer. We hypothesize that patients receiving radiation or chemotherapy at the time of analysis will report higher levels of sleep disturbance than those receiving no current adjuvant treatment. Our secondary aim was to investigate the association of sleep disturbance severity with the severity of other self-reported symptoms, including pain, nausea, fatigue, anxiety, depressive symptoms, and physical and social functioning in patients with early-stage breast cancer by adjuvant treatment modality. The tertiary aim of this study was to investigate the association of sleep disturbance with patient and cancer characteristics such as age and BMI. We hypothesize that increased reports of sleep disturbance will be associated with higher BMI and lower age.

\section{Methods}

\section{Design}

This study employed a cross-sectional design using data collected at 3 months after initial surgical treatment during 
a longitudinal parent study investigating treatment-induced nausea and vomiting and its genetic underpinnings in women with early-stage breast cancer. Study participants were recruited in the preoperative holding area of a teaching hospital in western Pennsylvania by trained members of the research team between April 2018 and March 2020.

\section{Inclusion and exclusion criteria}

Participants were eligible for recruitment to the parent study if they were female; between the ages of 18 and 90 years; diagnosed with early-stage breast cancer; classified as stage I, II, or IIIa; and scheduled for breast cancer surgery. Exclusion criteria for the parent study included a history of neurologic conditions such as stroke, head injury, spinal cord injury, or intracerebral hemorrhage. A total of 156 participants are included in this analysis, as this represented all participants who had responded to the 3-month survey as of March 2020, as this time point represents the period in which participants were likely to be receiving their first adjuvant therapy. Surveys collected after this were not included due to the potential confounding effects of the COVID-19 pandemic response on symptom burden in this population.

\section{Data collection}

Qualtrics survey software (Qualtrics@2020, Provo, UT) was used for all data collection and entry. Participants were recruited in the preoperative holding area following protocols approved by the University of Pittsburgh institutional review board. Data collected from the participant in the preoperative holding area included (1) age, (2) race, (3) smoking status, and (4) type of surgery. Age and BMI were obtained from participant's electronic medical record.

Participants were contacted after surgery on either a weekly or monthly basis either by telephone or email to respond to a survey administered by trained study staff. Patient-reported outcomes at 3 months post-surgery were used in this study, as this time point represents the period in which participants were likely to be receiving their first adjuvant therapy.

\section{Measures}

Information on adjuvant treatment modality at the time of the survey was collected from the medical record. Participants receiving radiation or chemotherapy were classified as such being their primary adjuvant treatment. Participants receiving AI therapy not in conjunction with chemotherapy or radiation were placed in the AI group.
Participants who had not begun adjuvant treatment yet or would not be receiving any adjuvant treatment were grouped into the no adjuvant treatment group.

Patient-reported outcomes were used for symptom measurement in this analysis. Pain and nausea severity were each measured on an 11-point numerical rating scale (NRS), with " 0 " indicating no pain or nausea and " 10 " indicating the worst pain or nausea ever experienced. Sleep and co-occurring symptoms were assessed using the Patient-Reported Outcomes Measurement Information System (PROMIS®-29 Profile v2.0). The PROMIS ${ }^{\circledR}$ is a National Institute of Health initiative to develop standardized items that measure feelings, function, and perceptions. PROMIS $®-29$ includes brief, valid assessments for sleep disturbance, anxiety, depressive symptoms, fatigue, and pain interference as well as physical function and ability to participate in social roles and activities [26]. Norm based T-scores have been developed, with a score of 50 representing the mean of the general population. T-scores for symptoms were calculated from participant responses to the PROMIS® subscales according to validated protocols for the PROMIS® reporting tool. For sleep disturbance, anxiety, depressive symptoms, fatigue, and pain interference, a score above 50 indicates a worse outcome as compared to the general population. A score below 50 indicates a worse outcome for physical function and ability to participate in social roles and activities [27].

\section{Statistical analysis}

Data were analyzed using IBM® SPSS $®$ Statistics for Windows (version 25, IBM Corp., Armonk, NY). An alpha level of 0.05 was used for all statistical tests. Comparative procedures were used to compare patient demographics across treatment groups. There were no outliers in sleep disturbance T-score by adjuvant treatment group as assessed by boxplot, with an outlier being defined as falling greater than 3 box lengths from the edge of the box in the boxplot. The histogram of studentized residuals from a univariate analysis of variance of sleep disturbance t-score by treatment group indicated approximate normality. The assumption of homogeneity of variance in sleep disturbance T-scores by adjuvant treatment group was met, as assessed by Levene's test $(p=0.41)$. Levene's test showed homogeneity of variance in age $(p=0.16)$ and BMI $(p=0.28)$ among treatment groups, and there were no significant differences in age $(p=0.13)$ or BMI $(p=0.67)$ among treatment groups. Fischer's exact test showed no significant differences in race by treatment group $(p=0.39)$ or in breast cancer surgery type by treatment group $(p=0.41)$.

Analysis of variance (ANOVA) was used to determine differences in mean sleep disturbance T-scores between the radiation, chemotherapy, $\mathrm{AI}$, and no adjuvant treatment groups. A post hoc multiple comparison procedure using 
Dunnett's t-test was used to compare sleep disturbance between each treatment group and the no adjuvant treatment group.

Multivariate regression was performed to assess the effect of sleep disturbance on other symptom measures collectively, stratified by adjuvant treatment group. Then, univariate linear regression was performed to assess the effect of sleep disturbance (as the independent variable) on each other reported symptom individually (as the dependent variable) within each adjuvant treatment group. Visual inspection of a histogram showed normality of the residuals for each symptom T-score pairing. The Pearson's correlation coefficient was also calculated to determine the relationship between BMI, age, and sleep disturbance T-score.

\section{Results}

\section{Demographic and clinical characteristics}

The sample for this study included 156 participants who responded to the 3-month assessment following surgery for early-stage breast cancer. The average age of participants was 59.10 years, with an average BMI of $29.56 \mathrm{~kg} /$ $\mathrm{m}^{2}$. A description of participant demographic and clinical characteristics by adjuvant treatment group can be found in Table 1.

\section{Sleep disturbance across treatments}

Mean sleep disturbance T-scores for each treatment group can be found in Table 2. At the 3-month assessment, there was a significant difference in mean sleep disturbance T-scores among treatment groups $(p=0.049)$. Specifically, there were significant differences in mean sleep disturbance T-scores between the chemotherapy group and no adjuvant treatment groups $(p=0.027)$ and the radiation group and no adjuvant treatment group $(p=0.038)$. No significant difference was observed between the AI group and the no adjuvant treatment group $(p=0.147)$.

\section{Association between sleep disturbance and other symptoms}

Scores for each symptom measure by treatment group are detailed in Table 3. In the group with no adjuvant treatment, multivariate regression showed a significant

Table 2 Sleep disturbance across treatments

\begin{tabular}{lclll}
\hline $\begin{array}{l}\text { Mean T-score by } \\
\text { treatment }\end{array}$ & $\mathrm{n}$ & Mean T-score & $\begin{array}{l}\text { Standard } \\
\text { deviation }\end{array}$ & $\begin{array}{l}95 \% \\
\text { confidence } \\
\text { intervals }\end{array}$ \\
\hline Chemotherapy & 24 & 50.39 & 9.15 & $46.52-51.89$ \\
Radiation & 47 & 49.21 & 9.13 & $46.53-54.24$ \\
Aromatase Inhibitor & 26 & 48.72 & 7.34 & $45.68-51.75$ \\
$\quad \begin{array}{l}\text { No adjuvant treat- } \\
\quad \text { ment }\end{array}$ & 59 & 45.50 & 8.21 & $43.36-47.64$ \\
$\quad$ Total sample & 156 & 47.90 & 8.66 & $46.53-49.28$ \\
\hline
\end{tabular}

Table 1 Sample characteristics for 156 women with early-stage breast cancer

\begin{tabular}{|c|c|c|c|c|c|c|}
\hline \multirow{2}{*}{$\frac{\text { Characteristic }}{\mathrm{n}(\%)}$} & \multirow{2}{*}{$\begin{array}{l}\text { No adjuvant treatment } \\
59(37.8)\end{array}$} & \multirow{2}{*}{$\begin{array}{l}\text { Chemotherapy } \\
24(15.4)\end{array}$} & \multirow{2}{*}{$\frac{\text { Radiation }}{47(30.1)}$} & \multirow{2}{*}{$\frac{\text { Aromatase inhibitor }}{26(16.7)}$} & \multicolumn{2}{|c|}{ Test statistic } \\
\hline & & & & & & \\
\hline \multicolumn{5}{|c|}{ Sociodemographic characteristics, mean (SD) } & $F$ & $p$ \\
\hline Age (years) & $58.51(13.70)$ & $56.67(12.26)$ & $57.48(11.60)$ & $63.60(9.42)$ & 1.89 & 0.13 \\
\hline $\mathrm{BMI}\left(\mathrm{kg} / \mathrm{m}^{2}\right)$ & $28.83(6.98)$ & $29.51(5.68)$ & $29.56(9.47)$ & $30.45(7.36)$ & 0.52 & 0.67 \\
\hline \multicolumn{5}{|l|}{ Race, n (column \%) } & \multicolumn{2}{|l|}{$p$} \\
\hline White & $49(84.5)$ & $19(79.2)$ & $44(95.7)$ & $23(88.5)$ & 0.39 & \\
\hline African-American & $9(15.5)$ & $3(12.5)$ & $1(2.2)$ & $3(11.5)$ & & \\
\hline Asian & $0(0)$ & $2(8.3)$ & $1(2.2)$ & $0(0)$ & & \\
\hline \multicolumn{5}{|l|}{ Surgery type, n (column \%) } & \multicolumn{2}{|l|}{$p$} \\
\hline Mass excision & $0(0.0)$ & $0(0.0)$ & $1(2.1)$ & 0 & 0.41 & \\
\hline Segmental mastectomy & $42(71.2)$ & $16(66.7)$ & $28(59.6)$ & $18(69.2)$ & & \\
\hline Unilateral total mastectomy & $5(8.5)$ & $6(25.0)$ & $10(21.3)$ & $4(15.4)$ & & \\
\hline Bilateral total mastectomy & $12(20.3)$ & $2(8.3)$ & $7(14.3)$ & $4(15.4)$ & & \\
\hline \multicolumn{5}{|l|}{ Smoking status, $\mathrm{n}$ (column \%) } & \multicolumn{2}{|l|}{$p$} \\
\hline Non-smoker & $36(78.3)$ & $11(61.1)$ & $30(81.1)$ & $10(52.6)$ & 0.15 & \\
\hline Current smoker & $3(6.5)$ & $1(5.6)$ & $1(2.7)$ & $1(5.3)$ & & \\
\hline Former smoker & $7(15.2)$ & $6(33.3)$ & $6(16.2)$ & $8(42.1)$ & & \\
\hline
\end{tabular}


Table 3 Symptoms across adjuvant treatment groups in patients with breast cancer

\begin{tabular}{|c|c|c|c|}
\hline & Mean T-score & Standard deviation & $95 \%$ confidence intervals \\
\hline \multicolumn{4}{|c|}{ Physical function by adjuvant treatment } \\
\hline Chemotherapy & 47.04 & 8.09 & $43.63-50.46$ \\
\hline Radiation & 49.46 & 8.92 & $46.84-52.08$ \\
\hline Aromatase inhibitor & 50.67 & 9.33 & $46.82-54.53$ \\
\hline No adjuvant treatment & 50.13 & 8.17 & $48.00-52.26$ \\
\hline \multicolumn{4}{|c|}{ Anxiety by adjuvant treatment } \\
\hline Chemotherapy & 50.39 & 8.86 & $46.64-54.51$ \\
\hline Radiation & 48.20 & 9.97 & $45.27-51.13$ \\
\hline Aromatase inhibitor & 47.72 & 8.52 & $44.20-51.23$ \\
\hline No adjuvant treatment & 46.44 & 7.58 & $44.46-48.41$ \\
\hline \multicolumn{4}{|c|}{ Depression by adjuvant treatment } \\
\hline Chemotherapy & 49.39 & 7.67 & $46.15-52.63$ \\
\hline Radiation & 46.06 & 7.34 & $43.91-48.22$ \\
\hline Aromatase inhibitor & 44.76 & 6.22 & $42.19-47.33$ \\
\hline No adjuvant treatment & 44.70 & 6.12 & $43.10-46.29$ \\
\hline \multicolumn{4}{|c|}{ Fatigue by adjuvant treatment } \\
\hline Chemotherapy & 55.43 & 10.13 & $51.16-59.71$ \\
\hline Radiation & 54.74 & 10.35 & $51.70-57.78$ \\
\hline Aromatase inhibitor & 47.07 & 8.59 & $43.53-50.62$ \\
\hline No adjuvant treatment & 49.00 & 9.57 & $46.51-51.50$ \\
\hline \multicolumn{4}{|c|}{ Ability to participate in social roles by adjuvant treatment } \\
\hline Chemotherapy & 54.09 & 10.46 & $49.68-58.51$ \\
\hline Radiation & 53.33 & 10.50 & $50.25-56.41$ \\
\hline Aromatase inhibitor & 55.80 & 10.60 & $51.42-60.17$ \\
\hline No adjuvant treatment & 55.44 & 9.80 & $52.89-58.00$ \\
\hline \multicolumn{4}{|c|}{ Pain interference by adjuvant treatment } \\
\hline Chemotherapy & 48.28 & 9.55 & $44.25-52.32$ \\
\hline Radiation & 50.27 & 10.09 & $47.31-53.23$ \\
\hline Aromatase inhibitor & 46.63 & 9.23 & $42.82-50.44$ \\
\hline \multirow[t]{2}{*}{ No adjuvant treatment } & 46.18 & 8.11 & $44.07-48.29$ \\
\hline & $\begin{array}{l}\text { Mean numeric rating } \\
\text { scale score }\end{array}$ & Standard deviation & $95 \%$ confidence intervals \\
\hline \multicolumn{4}{|c|}{ Pain severity by adjuvant treatment } \\
\hline Chemotherapy & 2.29 & 2.77 & $1.12-3.46$ \\
\hline Radiation & 2.74 & 2.45 & $2.02-3.47$ \\
\hline Aromatase inhibitor & 1.92 & 2.58 & $0.85-2.99$ \\
\hline No adjuvant treatment & 1.61 & 2.23 & $1.03-2.19$ \\
\hline \multicolumn{4}{|c|}{ Nausea severity by adjuvant treatment } \\
\hline Chemotherapy & 2.58 & 3.20 & $1.23-3.94$ \\
\hline Radiation & 1.15 & 2.10 & $0.53-1.77$ \\
\hline Aromatase inhibitor & 1.20 & 2.43 & $0.20-2.20$ \\
\hline No adjuvant treatment & 0.47 & 1.19 & $0.16-0.79$ \\
\hline
\end{tabular}

effect of sleep disturbance on other symptom measures collectively $\left(\mathrm{F}=3.871, p=0.001, \eta^{2}=0.382\right)$. Univariate regression established that sleep disturbance was significantly associated with pain severity $(\beta=0.358, p=0.005)$ as well as nausea severity $(\beta=0.348, p=0.007)$. Sleep disturbance was also significantly associated with pain interference $(\beta=0.403, p=0.002)$ and fatigue $(\beta=0.484$, $p<0.001)$.

In the radiation group, multivariate regression showed a significant effect of sleep disturbance on other symptom measures collectively $\left(\mathrm{F}=3.600, p=0.003, \eta^{2}=0.431\right)$. Univariate regression established that sleep disturbance 
was significantly associated with anxiety $(\beta=0.508$, $p<0.001)$, depressive symptoms $(\beta=0.422, p=0.003)$, fatigue $(\beta=0.444, p=0.002)$, pain interference $(\beta=0.548$, $p<0.001)$, as well as pain severity $(\beta=0.524, p<0.001)$, and nausea severity $(\beta=0.405, p=0.005)$. Sleep disturbance was also significantly negatively associated with physical function $(\beta=-0.497, p<0.001)$ and ability to participate in social roles and activities $(\beta=-0.533, p<0.001)$.

In the chemotherapy group, multivariate regression illustrated a trend towards an effect of sleep disturbance on other symptom measures collectively, but this association did not reach significance $\left(\mathrm{F}=0.443, p=0.073, \eta^{2}=0.557\right)$. However, univariate regression established that sleep disturbance was significantly associated with anxiety $(\beta=0.608, p=0.002)$ and depressive symptoms ( $\beta=0.630, p=0.001)$. Ability to participate in social roles and activities $(\beta=-0.492, p=0.015)$ was significantly negatively associated with sleep disturbance in this group.

In the AI group, multivariate regression showed a significant effect of sleep disturbance on other symptom measures collectively $\left(\mathrm{F}=0.435, p=0.049, \eta^{2}=0.565\right)$. Sleep disturbance was associated with fatigue $(\beta=0.575, p=0.003)$. Sleep disturbance was not significantly associated with any other symptoms in this group. Results for univariate regression can be found in Table 4 .
Table 4 Regression results associating sleep disturbance with co-occurring symptoms by adjuvant treatment group

\begin{tabular}{|c|c|c|c|}
\hline Symptom & $\beta$ & $\mathrm{t}$ & $\mathrm{p}$-value \\
\hline \multicolumn{4}{|l|}{ No adjuvant treatment } \\
\hline Physical function & -0.066 & -0.497 & 0.621 \\
\hline Anxiety & 0.164 & 1.251 & 0.216 \\
\hline Depression & 0.213 & 1.642 & 0.106 \\
\hline Fatigue & 0.484 & 4.171 & $0.001 *$ \\
\hline Ability to participate in social roles and activities & -0.169 & -1.297 & 0.200 \\
\hline Pain interference & 0.403 & 3.327 & $0.002 *$ \\
\hline Pain severity & 0.358 & 2.894 & $0.005^{*}$ \\
\hline Nausea severity & 0.348 & 2.801 & $0.007 *$ \\
\hline \multicolumn{4}{|l|}{ Chemotherapy } \\
\hline Physical function & -0.150 & -0.713 & 0.483 \\
\hline Anxiety & 0.608 & 3.594 & $0.002 *$ \\
\hline Depression & 0.630 & 3.804 & $0.001^{*}$ \\
\hline Fatigue & 0.205 & 0.980 & 0.338 \\
\hline Ability to participate in social roles and activities & -0.492 & -2.648 & $0.015^{*}$ \\
\hline Pain interference & 0.388 & 1.972 & 0.061 \\
\hline Pain severity & 0.120 & 0.568 & 0.576 \\
\hline Nausea severity & 0.037 & 0.175 & 0.863 \\
\hline \multicolumn{4}{|l|}{ Radiation } \\
\hline Physical function & -0.497 & -3.834 & $<0.001^{*}$ \\
\hline Anxiety & 0.508 & 3.961 & $<0.001^{*}$ \\
\hline Depression & 0.422 & 3.119 & $0.003 *$ \\
\hline Fatigue & 0.444 & 3.325 & $0.002 *$ \\
\hline Ability to participate in social roles and activities & -0.533 & -4.224 & $<0.001^{*}$ \\
\hline Pain interference & 0.548 & 4.396 & $0.001 *$ \\
\hline Pain severity & 0.524 & 4.124 & $<0.001^{*}$ \\
\hline Nausea severity & 0.405 & 2.972 & $0.005 *$ \\
\hline \multicolumn{4}{|l|}{ Aromatase inhibitor } \\
\hline Physical function & -0.204 & -1.026 & 0.316 \\
\hline Anxiety & 0.306 & 1.542 & 0.137 \\
\hline Depression & 0.255 & 1.265 & 0.219 \\
\hline Fatigue & 0.575 & 3.371 & $0.003 *$ \\
\hline Ability to participate in social roles and activities & -0.270 & -1.346 & 0.191 \\
\hline Pain interference & 0.051 & 0.243 & 0.810 \\
\hline Pain severity & 0.182 & 0.887 & -0.384 \\
\hline Nausea severity & 0.064 & 0.306 & 0.762 \\
\hline
\end{tabular}

*Significant at an $\alpha$-level of 0.05 . 


\section{Sleep disturbance with participant demographics}

An assessment of the total sample, age was significantly negatively correlated with sleep disturbance $(r=-0.204$, $p=0.008$ ). No significant association was found between sleep disturbance and BMI.

\section{Discussion}

Consistent with prior research [1, 17, 18], our findings supported the hypothesis that breast cancer patients undergoing chemotherapy report higher levels of sleep disturbance than those not undergoing treatment. We also concluded that breast cancer patients undergoing radiation report higher levels of sleep disturbance than those not undergoing treatment, although the level of subjective sleep disturbance is similar between those undergoing chemotherapy and radiation. While a prior study found that insomnia was more likely to be discussed with cancer patients at appointments with a transplant team or medical oncologists, when compared to other provider teams [28], this finding highlights the need for all providers, including radiation oncologists, to assess sleep disturbance in their patients, as it may be associated with a variety of treatments.

Other studies have suggested that sleep disturbance may occur in a symptom cluster along with fatigue and pain in patients undergoing chemotherapy [4], as well as in conjunction with a variety of other symptoms including the severity of depressive symptoms, anxiety, and nausea, and decreased quality of life [10-13], although the co-occurrence of these symptoms has not been as thoroughly characterized in those receiving radiation. For patients receiving radiation in this study, sleep disturbance was associated with pain, pain interference, nausea, anxiety, depressive symptoms, fatigue, decreased physical function, and decreased ability to participate in social roles, indicating a central role for sleep disturbance in symptom burden for this population. The large number of co-occurring symptoms for the women in the radiation group highlights the need for overall symptom control.

In the women undergoing adjuvant chemotherapy, the results of multivariate regression showed a trend towards an effect of sleep disturbance on collective symptom measures, but this relationship did not reach significance. However, given that the chemotherapy group was the smallest adjuvant treatment group, with a sample size of 27 , it is possible that this lack of significance was due to a small sample size. In the univariate linear regression in the chemotherapy group, sleep disturbance was only associated with higher levels of anxiety and depressive symptoms as well as lower ability to participate in social roles. This indicates the possibility for a different underlying mechanism of sleep disturbance in women receiving chemotherapy and the potential need to focus on the impact of psychological and social factors associated with chemotherapy treatment as they affect symptom development. This is consistent with findings associating sleep disturbance in patients receiving chemotherapy for breast cancer with factors such as higher trait anxiety and higher levels of education [10].

In women undergoing AI therapy, sleep disturbance was only associated with fatigue. Given that AI therapy is associated with menopausal symptoms such as hot flashes [29], it is possible that co-occurring symptoms in this group were not captured by this study. In participants receiving no adjuvant therapy, sleep disturbance was associated with pain, pain interference, nausea, and fatigue.

The difference in symptoms co-occurring with sleep disturbance among treatment groups suggests that etiology of sleep disturbance may differ across treatment groups, and interventions for sleep disturbance may need to be tailored to both treatment modality and associated symptoms. Inflammatory pathways have been implicated in the severity of symptoms, including sleep disturbance, in patients receiving chemotherapy and radiation [30-32]. Additionally, there is evidence that sleep deficit can increase the activity of inflammatory pathways and oxidative stress, indicating that sleep disturbance may play multiple roles in the development of symptoms clusters [33]. There is also evidence suggesting that social factors, perhaps influenced by treatment modality, also influence sleep disturbance [34, 35]. Further research regarding the interaction of biological and social factors influencing symptom burden needs to be undertaken in a treatment-specific fashion to uncover these relationships and allow for targeted intervention strategies.

Additionally, the associations between sleep disturbance and other symptoms including pain, nausea, depression, anxiety, decreased physical function, and difficulty participating in social roles and activities, especially in the radiation group, suggest the need for investigation regarding how symptom burden may be treated in a holistic manner. While some research indicates that there is no clear evidence that treatment of one facet in the fatigue-depression-sleep disturbance symptom cluster is effective in mitigating other symptoms [36], other research suggests that therapy intended to relieve a single symptom, such as anxiety or depression, may be useful in relieving sleep disturbance [37]. However, recent clinical practice guidelines on the use of integrative relief for symptom burden in cancer using review of recent literature list yoga as the only integrative therapy recommended for sleep disturbance [38]. The results of our analysis linking sleep disturbance to other symptoms suggest that the treatment of sleep disturbance may be a step towards a holistic approach to relieving symptom burden.

Our analysis supported the finding that sleep disturbance in breast cancer patients is associated with younger age. However, in contrast to former literature, no association was found between BMI and reported sleep disturbance. 
A limitation of this study was the lack of objective sleep data. Prior research using both objective and subjective sleep data in this population has found discrepancies in the two sources of sleep data $[39,40]$, with one study finding no differences in electroencephalogram parameters between breast cancer patients who reported insomnia and those who did not [41]. Given the discrepancies between objective and subjective data on sleep disturbance in this population, caution must be used when applying the results of this analysis to objective sleep quality. The focus of the results of this study is on the patient-reported outcomes regarding sleep disturbance symptoms. Another study limitation was the relatively low number of minorities included in the analysis. Given the evidence on disparities in treatment for sleep disturbance in this population, care should be taken to describe the symptom experiences of minorities going forward.

Given the cross-sectional design of this analysis, future research should measure changes in sleep disturbance over time in this population and how it may be confounded by treatment factors. Investigation into how sleep disturbance may change over the course of treatment in this population would be informative given recent research suggesting that patients with relatively low or high sleep disturbance severity before chemotherapy treatment tend to remain in the same severity group at the end of treatment [42].

Patients undergoing breast cancer treatment should be thoroughly evaluated for sleep disturbance. The association of sleep disturbance with other symptoms, including pain, nausea, anxiety, depression, decreased physical function, and difficulty participating in social roles, indicates sleep disturbance's integral role in the complex interplay between symptoms experienced by patients with breast cancer. Treatment of sleep disturbance should be considered as a method to alleviate symptom burden in this population.

\section{Author contribution N/A.}

Funding This study was funded by the National Institute of Nursing Research NR0196556 for Genomic Underpinnings Treatment Induced Nausea and Vomiting in Breast Cancer and T32NR00975915 for Targeted Research and Academic Training Program for Nurses in Genomics.

Data Availability All primary data are housed at the University of Pittsburgh School of Nursing and are available on request.

Code availability Data were analyzed using IBM® SPSS $₫$ Statistics for Windows (version 25, IBM Corp., Armonk, NY).

\section{Declarations}

Ethics approval The methodology for this study was approved by the Human Research Protection Office of the University of Pittsburgh (The University of Pittsburgh IRB, protocol number 19030259).
Consent to participate Participants were recruited following protocols approved by the University of Pittsburgh institutional review board.

Consent for publication N/A.

Conflict of interest The authors declare no competing interests.

\section{References}

1. Whisenant M, Wong B, Mitchell SA, Beck SL, Mooney K (2017) Distinct trajectories of fatigue and sleep disturbance in women receiving chemotherapy for breast cancer. Oncol Nurs Forum 44(6):739-750. https://doi.org/10.1188/17.ONF.739-750

2. Dhruva A, Paul SM, Cooper BA, Lee K, West C, Aouizerat BE, Dunn LB, Swift PS, Wara W, Miaskowski C (2012) A longitudinal study of measures of objective and subjective sleep disturbance in patients with breast cancer before, during, and after radiation therapy. J Pain Symptom Manage 44(2):215-228. https://doi.org/ 10.1016/j.jpainsymman.2011.08.010

3. Leysen L, Lahousse A, Nijs J, Adriaenssens N, Mairesse O, Ivakhnov S, Bilterys T, Van Looveren E, Pas R, Beckwée D (2019) Prevalence and risk factors of sleep disturbances in breast cancer survivors: systematic review and meta-analyses. Support Care Cancer 27(12):4401-4433. https://doi.org/10.1007/ s00520-019-04936-5

4. Albusoul RM, Berger AM, Gay CL, Janson SL, Lee KA (2017) Symptom clusters change over time in women receiving adjuvant chemotherapy for breast cancer. J Pain Symptom Manage 53(5):880-886. https://doi.org/10.1016/j.jpainsymman.2016.12. 332

5. Dodd MJ, Miaskowski C, Paul SM (2001) Symptom clusters and their effect on the functional status of patients with cancer. Oncol Nurs Forum 28(3):465-470

6. Wang JP, Lu SF, Guo LN, Ren CG, Zhang ZW (2019) Poor preoperative sleep quality is a risk factor for severe postoperative pain after breast cancer surgery: a prospective cohort study. Medicine (Baltimore) 98(44):e17708. https://doi.org/10.1097/MD.00000 00000017708

7. Van Onselen C, Aouizerat BE, Dunn LB, Paul SM, West C, Hamolsky D, Lee K, Melisko M, Neuhaus J, Miaskowski C (2013) Differences in sleep disturbance, fatigue and energy levels between women with and without breast pain prior to breast cancer surgery. Breast 22(3):273-276. https://doi.org/10.1016/j.breast.2012.07.007

8. Peoples AR, Pigeon WR, Li D, Garland SN, Perlis ML, Inglis JE, Vinciguerra V, Anderson T, Evans LS, Wade JL, Ossip DJ, Morrow GR, Wolf JR (2021) Association between pretreatment sleep disturbance and radiation therapy-induced pain in 573 women with breast cancer. J Pain Symptom Manage 61(2):254-261. https://doi.org/10.1016/j.jpainsymman.2020.07.041

9. Liu L, Mills PJ, Rissling M, Fiorentino L, Natarajan L, Dimsdale JE, Sadler GR, Parker BA, Ancoli-Israel S (2012) Fatigue and sleep quality are associated with changes in inflammatory markers in breast cancer patients undergoing chemotherapy. Brain Behav Immun 26(5):706-713. https://doi.org/10.1016/j.bbi.2012.02.001

10. Mark S, Cataldo J, Dhruva A, Paul SM, Chen LM, Hammer MJ, Levine JD, Wright F, Melisko M, Lee K, Conley YP, Miaskowski C (2017) Modifiable and non-modifiable characteristics associated with sleep disturbance in oncology outpatients during chemotherapy. Support Care Cancer 25(8):2485-2494. https://doi.org/ 10.1007/s00520-017-3655-2

11. Steel JL, Terhorst L, Collins KP, Geller DA, Vodovotz Y, Kim J, Krane A, Antoni M, Marsh JW, Burke LE, Butterfield LH, Penedo 
FJ, Buysse DJ, Tsung A (2018) Prospective analyses of cytokine mediation of sleep and survival in the context of advanced cancer. Psychosom Med 80(5):483-491. https://doi.org/10.1097/PSY. 0000000000000579

12. Jung D, Lee KM, Kim WH, Lee JY, Kim TY, Im SA, Lee KH, Spiegel D, Hahm BJ (2016) Longitudinal association of poor sleep quality with chemotherapy-induced nausea and vomiting in patients with breast cancer. Psychosom Med 78(8):959-965. https://doi.org/10.1097/PSY.0000000000000372

13. Peoples AR, Roscoe JA, Block RC, Heckler CE, Ryan JL, Mustian KM, Janelsins MC, Peppone LJ, Moore DF Jr, Coles C, Hoelzer KL, Morrow GR, Dozier AM (2017) Nausea and disturbed sleep as predictors of cancer-related fatigue in breast cancer patients: a multicenter NCORP study. Support Care Cancer 25(4):12711278. https://doi.org/10.1007/s00520-016-3520-8

14. Tejada M, Viele C, Kober KM, Cooper BA, Paul SM, Dunn LB, Hammer MJ, Wright F, Conley YP, Levine JD, Miaskowski C (2019) Identification of subgroups of chemotherapy patients with distinct sleep disturbance profiles and associated co-occurring symptoms. Sleep 42(10):zsz151. https://doi.org/10.1093/sleep/ zsz151

15. Berger AM, Kupzyk KA, Djalilova DM, Cowan KH (2019) Breast Cancer Collaborative Registry informs understanding of factors predicting sleep quality. Support Care Cancer 27(4):1365-1373. https://doi.org/10.1007/s00520-018-4417-5

16. Berger AM, Matthews EE, Kenkel AM (2017) Management of sleep-wake disturbances comorbid with cancer. Oncology (Williston Park) 31(8):610-617

17. Alfano CM, Lichstein KL, Vander Wal GS, Smith AW, Reeve BB, McTiernan A, Bernstein L, Baumgartner KB, Ballard-Barbash R (2011) Sleep duration change across breast cancer survivorship: associations with symptoms and health-related quality of life. Breast Cancer Res Treat 130(1):243-254. https://doi.org/10. 1007/s10549-011-1530-2

18. Bower JE, Ganz PA, Irwin MR, Kwan L, Breen EC, Cole SW (2011) Inflammation and behavioral symptoms after breast cancer treatment: do fatigue, depression, and sleep disturbance share a common underlying mechanism? J Clin Oncol 29(26):3517-3522. https://doi.org/10.1200/JCO.2011.36.1154

19. Miaskowski C, Paul SM, Cooper BA, Lee K, Dodd M, West C, Aouizerat BE, Dunn L, Swift PS, Wara W (2011) Predictors of the trajectories of self-reported sleep disturbance in men with prostate cancer during and following radiation therapy. Sleep 34(2):171-179. https://doi.org/10.1093/sleep/34.2.171

20. Chow S, Wan BA, Pidduck W, Zhang L, DeAngelis C, Chan S, Yee C, Drost L, Leung E, Sousa P, Lewis D, Lam H, Chow R, Lock M, Chow E (2019) Symptom clusters in patients with breast cancer receiving radiation therapy. Eur J Oncol Nurs 42:14-20. https://doi.org/10.1016/j.ejon.2019.07.004

21. Desai K, Mao JJ, Su I, Demichele A, Li Q, Xie SX, Gehrman PR (2013) Prevalence and risk factors for insomnia among breast cancer patients on aromatase inhibitors. Support Care Cancer 21(1):43-51. https://doi.org/10.1007/s00520-012-1490-z

22. Bischel LE, Ritchie C, Kober KM, Paul SM, Cooper BA, Chen LM, Levine JD, Hammer M, Wright F, Miaskowski C (2016). Age differences in fatigue, decrements in energy, and sleep disturbance in oncology patients receiving chemotherapy. Eur J Oncol Nurs 115-23. https://doi.org/10.1016/j.ejon.2016.07.002

23. Janz NK, Mujahid M, Chung LK, Lantz PM, Hawley ST, Morrow M, Schwartz K, Katz SJ (2007) Symptom experience and quality of life of women following breast cancer treatment. J Womens Health (Larchmt) 16(9):1348-1361. https://doi.org/10.1089/jwh. 2006.0255

24. Van Onselen C, Cooper BA, Lee K, Dunn L, Aouizerat BE, West C, Dodd M, Paul S, Miaskowski C (2012) Identification of distinct subgroups of breast cancer patients based on self-reported changes in sleep disturbance. Support Care Cancer 20(10):2611-2619. https://doi.org/10.1007/s00520-012-1381-3

25. Beverly CM, Naughton MJ, Pennell ML, Foraker RE, Young G, Hale L, Feliciano EMC, Pan K, Crane TE, Danhauer SC, Paskett ED (2018) Change in longitudinal trends in sleep quality and duration following breast cancer diagnosis: results from the Women's Health Initiative. NPJ Breast Cancer 4:15. https://doi. org/10.1038/s41523-018-0065-7

26. Cella D, Riley W, Stone A, Rothrock N, Reeve B, Yount S, Amtmann D, Bode R, Buysse D, Choi S, Cook K, Devellis R, DeWalt D, Fries JF, Gershon R, Hahn EA, Lai JS, Pilkonis P, Revicki D, Rose M, Weinfurt K, Hays R; PROMIS Cooperative Group (2010) The Patient-Reported Outcomes Measurement Information System (PROMIS) developed and tested its first wave of adult selfreported health outcome item banks: 2005-2008. J Clin Epidemiol 63(11):1179-1194. https://doi.org/10.1016/j.jclinepi.2010.04.011

27. Cella D, Choi SW, Condon DM, Schalet B, Hays RD, Rothrock NE, Yount S, Cook KF, Gershon RC, Amtmann D, DeWalt DA, Pilkonis PA, Stone AA, Weinfurt K, Reeve BB (2019) PROMIS ${ }^{\circledR}$ adult health profiles: efficient short-form measures of seven health domains. Value Health 22(5):537-544. https://doi.org/10.1016/j. jval.2019.02.004

28. Siefert ML, Hong F, Valcarce B, Berry DL (2014) Patient and clinician communication of self-reported insomnia during ambulatory cancer care clinic visits. Cancer Nurs 37(2):E51-E59. https:// doi.org/10.1097/NCC.0b013e318283a7bc

29. Gallicchio L, MacDonald R, Wood B, Rushovich E, Helzlsouer KJ (2012) Menopausal-type symptoms among breast cancer patients on aromatase inhibitor therapy. Climacteric 15(4):339-349. https://doi.org/10.3109/13697137.2011.620658

30. Kwekkeboom KL, Tostrud L, Costanzo E, Coe CL, Serlin RC, Ward SE, Zhang Y (2018) The role of inflammation in the pain, fatigue, and sleep disturbance symptom cluster in advanced cancer. J Pain Sympt Manag 55(5):1286-1295. https://doi.org/10. 1016/j.jpainsymman.2018.01.008

31. Liu L, Mills PJ, Rissling M, Fiorentino L, Natarajan L, Dimsdale JE, Sadler GR, Parker BA, Ancoli-Israel S (2012) Fatigue and sleep quality are associated with changes in inflammatory markers in breast cancer patients undergoing chemotherapy. Brain, behavior, and immunity 26(5):706-713. https://doi.org/10.1016/j.bbi. 2012.02.001

32. Sprod LK, Palesh OG, Janelsins MC, Peppone LJ, Heckler CE, Adams MJ, Morrow GR, Mustian KM (2010) Exercise, sleep quality, and mediators of sleep in breast and prostate cancer patients receiving radiation therapy. Commun Oncol 7(10):463471. https://doi.org/10.1016/s1548-5315(11)70427-2

33. Atrooz F, Salim S (2020) Sleep deprivation, oxidative stress and inflammation. Adv Protein Chem Struct Biol 119:309-336. https://doi.org/10.1016/bs.apcsb.2019.03.001

34. Wu I, Tsai W, McNeill LH, Lu Q (2020) The associations of selfstigma, social constraints, and sleep among Chinese American breast cancer survivors. Support Care Cancer 28(8):3935-3944. https://doi.org/10.1007/s00520-019-05233-x

35. Martin CM, Greene D, Harrell JP, Mwendwa DT, Williams CD, Horton S, Cradle M, Hudson BD, Taylor TR (2020) The impact of social constraints on insomnia among African-American breast cancer survivors: the mediating role of fear of recurrence. Psychooncology 29(8):1296-1302. https://doi.org/10.1002/pon.5435

36. Jain S, Boyd C, Fiorentino L, Khorsan R, Crawford C (2015) Are there efficacious treatments for treating the fatigue-sleep disturbance-depression symptom cluster in breast cancer patients? A Rapid Evidence Assessment of the Literature (REAL(@)). Breast Cancer (Dove Med Press) 7:267-291. https://doi.org/10.2147/ BCTT.S25014

37. Zeichner SB, Zeichner RL, Gogineni K, Shatil S, Ioachimescu O (2017) Cognitive behavioral therapy for insomnia, mindfulness, 
and yoga in patients with breast cancer with sleep disturbance: a literature review. Breast Cancer (Auckl) 11:1178223417745564. https://doi.org/10.1177/1178223417745564

38. Greenlee H, DuPont-Reyes MJ, Balneaves LG, Carlson LE, Cohen MR, Deng G, Johnson JA, Mumber M, Seely D, Zick SM, Boyce LM, Tripathy D (2017) Clinical practice guidelines on the evidence-based use of integrative therapies during and after breast cancer treatment. CA Cancer J Clin 67(3):194-232. https://doi. org/10.3322/caac. 21397

39. Enderlin CA, Coleman EA, Cole C, Richards KC, Kennedy RL, Goodwin JA, Hutchins LF, Mack K (2011) Subjective sleep quality, objective sleep characteristics, insomnia symptom severity, and daytime sleepiness in women aged 50 and older with nonmetastatic breast cancer. Oncol Nurs Forum 38(4):E314-E325. https://doi.org/10.1188/11.ONF.E314-E325

40. Kreutz C, Müller J, Schmidt ME, Steindorf K (2021) Comparison of subjectively and objectively assessed sleep problems in breast cancer patients starting neoadjuvant chemotherapy. Support Care Cancer 29(2):1015-1023. https://doi.org/10.1007/ s00520-020-05580-0

41. Reinsel RA, Starr TD, O’Sullivan B, Passik SD, Kavey NB (2015) Polysomnographic study of sleep in survivors of breast cancer. J Clin Sleep Med 11(12):1361-1370. https://doi.org/10.5664/jcsm. 5264

42. Fox RS, Ancoli-Israel S, Roesch SC, Merz EL, Mills SD, Wells KJ, Sadler GR, Malcarne VL (2020) Sleep disturbance and cancer-related fatigue symptom cluster in breast cancer patients undergoing chemotherapy. Support Care Cancer 28(2):845-855. https://doi.org/10.1007/s00520-019-04834-w

Publisher's note Springer Nature remains neutral with regard to jurisdictional claims in published maps and institutional affiliations. 